International Review of Research in Open and Distributed Learning

Volume 17, Number 2

February - 2016

\title{
Experience with a Massive Open Online Course in Rural Rwanda
}

${ }^{*}$ Christine Warugaba, M.D., MPH, *Brienna Naughton, M.P.H., Bethany Hedt-Gauthier, Ph.D., Ernest Muhirwa, B.Sc, and Cheryl L. Amoroso, M.P.H.

${ }^{*}$ [Co-first authors], Partners In Health, Harvard Medical School

\begin{abstract}
The growing utilization of massive open online courses (MOOCs) is opening opportunities for students worldwide, but the completion rate for MOOCs is low (Liyanagunawardena, Adams, \& Williams, 2013). Partners In Health (PIH) implemented a "flipped" MOOC in Rwanda that incorporated in-class sessions to facilitate participant completion.

In October 2013, PIH invited its employees, as well as those at the Ministry of Health, to participate in an online MOOC. Each site had at least one volunteer facilitator who accompanied participants throughout the course by providing course materials and facilitating the understanding of the online material during the weekly class sessions. Following the conclusion of the course, all participants were asked to complete an online survey.
\end{abstract}

A total of 38 out of 62 registered participants completed the survey and of these 38 participants, 20 (52.6\%) successfully finished the course. The number of in-person sessions attended was significantly associated with course completion ( $p<0.05$ ), and $85 \%$ who successfully completed the course attended at least three of seven sessions. Sixteen (80\%) participants believed that the completion of this course would help them with career advancement. Half of the participants (19 of $38,50 \%$ ) were employed with a position related to research. Other job titles included the following: nurses ( 4 of 38, 10.5\%), a pharmacist ( 1 of $38,2.6 \%$ ), a clinical psychologist ( 1 of $38,2.6 \%$ ), a dentist ( 1 of $38,2.6 \%$ ), and others (10 of 38 , 26.3\%). The job title was not significantly related to course completion.

Our experience, with a completion rate of over $50 \%$, yields several lessons for incorporating MOOCs into capacity-building programs to leverage the potential of online learning in resource-limited areas.

Keywords: online courses, flipped classroom, MOOC, rural education, low-resource education 


\section{Introduction}

The growing prevalence of free online courses, known as massive open online courses (MOOCs), is expected to shift the paradigm of education worldwide. By providing global access to world-class teachers and materials, online courses are revolutionizing the way that students learn, and re-classifying the very definition of a student (Friedman, 2013; Pappano, 2012). No longer must a student be able to afford tuition, or be limited by proximity or time, in order to access tertiary-level courses, since these free, selfpaced courses can open opportunities for any interested individual with access to the Internet.

While the potential for MOOCs to provide first-rate educational opportunities to students worldwide has been widely discussed (Friedman, 2013; Pappano, 2012), particularly for those not enrolled in formal educational programs, this potential has yet to be fully realized and barriers to implementation are not fully understood. Completion rates for the majority of MOOCs are less than 10\% (Liyanagunawardena, Adams, \& Williams, 2013), and according to a recent study of MOOCs offered on the Coursera platform, the majority of MOOC students are young, male, well-educated, employed, and from developed countries (Christensen et al., 2013). Little is known about the use of MOOCs in resource-limited settings, particularly in regards to continuing education for health professionals in Africa.

Some universities have also started drawing on the popularity of online courses by implementing their own "flipped classrooms", where lectures are pre-recorded by professors and assigned to students outside of class (Berrett, 2012; McLaughlin et al., 2014; Bishop \& Verleger, 2013). By leveraging the existing components of MOOCs, including video lectures, online forums, and tests, instructors blend this into class periods that are focused on active student engagement. The professors become less of the guiders of the course and more the facilitators of learning for participants.

Partners In Health (PIH), a Boston-based nonprofit organization, supports public health development and capacity building activities in three rural districts in Rwanda, in collaboration with the Rwanda Ministry of Health (MOH). As part of a continuing education initiative for health professionals, focusing on global health principles, the PIH-Rwanda Research Department recently offered its first flipped class to PIH and MOH staff. Although MOOCs have been noted to have great promise for public health education (Gooding, Klaas, Yager, \& Kanchanaraksa, 2013), the implementation of this course represents, to our knowledge, one of the first coordinated experiences of integrating a global health MOOC and a flipped classroom in a rural, low-resource, setting. PIH-Rwanda's experience in implementing this course can provide a unique perspective into the challenges and benefits associated with utilizing MOOCs in rural settings and provide guidance for other similar organizations hoping to deliver such courses for their staffs' continuing education.

\section{Contextualization and Methodology}

Coursera, a for-profit organization, is one of the largest organizations providing MOOCs, offering 715 courses from 108 institutions as of August 2014 ("Coursera," 2014). In October 2013, the University of 
Geneva introduced a MOOC on Coursera entitled "Global Health: An Interdisciplinary Overview," consisting of seven week-long segments followed by a three-week period for completion and grading of the final assessment. The course format consisted of weekly topics spanning broad thematic issues of global health with video lectures complemented by a course guide and readings, student assessments (short quizzes) and discussion forum activities. The short quizzes were distributed weekly and contributed to $20 \%$ of the final grade. The final assessment, composing $80 \%$ of the final grade, was an essay graded by peers. Each student was required to grade five other students' final assessments in order to successfully complete the course. A passing grade was $55 \%$.

\section{Local Offering of the MOOC}

The PIH-Rwanda Research Department, based at the PIH-Rwanda headquarters in a rural district, invited all PIH-Rwanda and $\mathrm{MOH}$ employees from the three PIH-supported districts (Rwinkwavu, Burera, and Kirehe) to join the in-person additional classes supporting the MOOC. There were no educational or content prerequisites and participation was optional. Each district had at least one volunteer facilitator, each of whom were PIH-Rwanda staff with varied educational backgrounds (one with a bachelor's degree, two with a Master in Public Health (MPH), and one with a medical degree (MD/MPH). Facilitators jointly composed weekly discussion questions, group activities, and additional lecture material for the class meetings with weekly calls to coordinate activities.

Only one PIH site (Rwinkwavu) had sufficient Internet connectivity for downloading the large online videos in a reasonable timeframe. The other two sites (Burera and Kirehe) had otherwise sufficient but unreliable Internet. Each week, a facilitator at Rwinkwavu downloaded the week's videos, subtitles, course guide, and required reading journal articles onto a flash drive which was transported to the other two sites through existing PIH transport mechanisms. After persistent challenges in downloading the content, the PIH team reached out to the course coordinator at the University of Geneva, who then provided the videos directly to PIH-Rwanda several days before the usual release online. The PIH team would then distribute the materials to the students who needed them on a weekly basis.

Once a week the participants and facilitators met in their respective sites for 1.5-2 hours after work hours. These weekly sessions were discussion-guided to clarify and expand upon the previous week's videos and course guide. Rarely, participants requested more information on a specific topic, in which case a facilitator presented a short lecture reviewing the material. The sessions primarily focused on active student engagement in the materials, and guided small group discussions and projects. Following classes, transportation was provided to the local town center because regular public transport was unavailable at the facilities. For the final assessment, the facilitators assisted in brainstorming and occasional editing as needed.

\section{Data Collection and Analysis}

Following the conclusion of the course, all participants who had registered for the course were asked to complete a facilitator-designed online survey. Developed by the PIH team, this survey examined demographic details of the participants, as well as quantitative and qualitative assessments of their 
participation. Data were collected from these surveys and basic descriptive statistics were performed using SPSS Version 17.

\section{Ethics Consideration}

The study was reviewed by the Partners In Health-Rwanda, Research Committee and was approved with reference number RC-0214-02. The online survey completed by the participants was anonymous and optional, and provided no benefit or detriment to the participants.

\section{Sample}

Of 62 who registered for the course, 38 completed the final survey (Table 1). Most participants (21 of 38 , $55 \%)$ were employed by $\mathrm{PIH}, 14$ (37\%) by $\mathrm{MOH}$, and 3 (8\%) did not report their employer.

The education levels of the participants varied, 15.8\% ( 3 of 38) reported their highest level of education as a high school diploma, while $84.2 \%$ (16 of 38 ) had bachelor's degrees. There were two students with postgraduate degrees, although they did not complete the course. Thirty-five participants (92\%) reported having taken a university class before, and 14 (37\%) had taken an online course.

Table 1

Participants Characteristics and Course Completion

\begin{tabular}{|c|c|c|c|c|c|}
\hline \multirow[b]{2}{*}{ Characteristic } & \multicolumn{2}{|c|}{ Completed course } & \multicolumn{2}{|c|}{ Did not complete course } & \multirow[b]{2}{*}{$p$-value } \\
\hline & $n$ & $\%$ & $n$ & $\%$ & \\
\hline Job Title & & & & & .403 \\
\hline Nurse & 1 & 5.3 & 3 & 17.6 & \\
\hline Research-related & 12 & 63.1 & 7 & 41.2 & \\
\hline Pharmacist & 1 & 5.3 & 0 & 0 & \\
\hline Clinical psychologist & 0 & 0 & 1 & 5.9 & \\
\hline Dentist & 0 & 0 & 1 & 5.9 & \\
\hline Other & 5 & 26.3 & 5 & 29.4 & \\
\hline Employer & & & & & .317 \\
\hline $\mathrm{PIH}$ & 13 & 68.4 & 8 & 50.0 & \\
\hline $\mathrm{MOH}$ & 6 & 31.6 & 8 & 50.0 & \\
\hline Highest level of education & & & & & .052 \\
\hline Diploma & 3 & 15.8 & 8 & 47.1 & \\
\hline Bachelors & 16 & 84.2 & 7 & 41.2 & \\
\hline
\end{tabular}




\begin{tabular}{llllll}
\hline Masters & 0 & 0 & 1 & 5.9 & \\
Ph.D. & 0 & 0 & 1 & 5.9 & .528 \\
Taken university course before & & & & & \\
$\quad$ Yes & 18 & 94.7 & 17 & 100 & .224 \\
$\quad$ No & 1 & 5.3 & 0 & 0 & \\
Taken online course before & & & & & \\
$\quad$ Yes & 9 & 47.4 & 5 & 29.4 & .013 \\
No & 10 & 52.6 & 12 & 70.6 & \\
In-person classes attended & & & & & \\
$0-2$ & 3 & 15 & 11 & 61.1 & \\
3-4 & 9 & 45 & 4 & 22.2 & .152 \\
5-7 & 8 & 40 & 3 & 16.7 & .307 \\
Challenges & & & & & N/A \\
Time commitment & 14 & 70 & 16 & 88.9 & .373 \\
Internet access & 7 & 35 & 4 & 22.2 & \\
Transportation & 0 & 0 & 0 & 0 & \\
Convenient class time & 9 & 45 & 10 & 55.6 & 47.4 \\
\hline Total Participants & 20 & 52.6 & 18 & & \\
\hline
\end{tabular}

Note. $p$-value $<.05$ indicates statistically significant result

\section{Results}

Twenty people (53\%) successfully completed the course. There was no significant difference in course completion by employer $(p=0.317)$.

The number of in-person classes attended was significantly associated with completion of the course $(p<$ .05). Other results shown in Table 2:

Table 2

Participant's Experience with the Course Among Those who Completed the Course

\section{Completed Course $(n=20)$}


Used online forum

Yes

$10 \quad 50$

No

10

50

Number of quizzes completed and passed

$0-2$

3-4

$5-7$

1

1

18

90

Ease of quizzes

Easy

3

15

Moderate

17

85

Difficult

0

0

Ease of the final paper

Easy

0

0

Moderate

19

Difficult

1

5

Time required per week

$<2$ hours

0

0

2-5 hours

16

80

$>5$ hours

4

20

Course will help their work

Yes

16

80

Maybe

4

20

No

0

0

Course will help career advancement

Yes

18

90

Maybe

2

10

No

0

0

Skills were acquired from the course

Yes

20

100 
No

Would have taken the course without PIH

organizing

Yes

Maybe

10

No

4

20

\section{Discussion}

This study includes a sample of individuals who enrolled in a flipped classroom learning experience that provided in-person support to complement an existing MOOC. With a completion rate of $52.6 \%$, well above the general MOOC completion rate of less than 10\% (Liyanagunawardena, Adams, \& Williams, 2013), our experience is a unique assessment of a flipped classroom in a rural area.

Additionally, this experience utilizing a MOOC as a mode to deliver continuing education for health researchers and professionals in a resource-limited setting highlights the benefits as well as the challenges that can inform the role that MOOCs can play in professional development in these settings. Internetbased continuing medical education has been found to be promising for content delivery and mastery, and in particular, Web-based interactive forums for these uses have been found effective at fostering an interactive learning environment (Curran \& Fleet, 2005). However, substantial barriers have been identified in regards to e-learning for health professionals, which are only further complicated by a rural, remote setting (Cobb, 2004; Childs, Blenkinsopp, Hall, \& Walton, 2005).

By incorporating in-class activities and key logistical and technical support into a MOOC, standard elearning is enhanced with the benefits of a MOOC-interactive quizzes and forums, self-guided and structured content, as well as the benefits of in-person technical, logistical, and educational support. Our experience highlights methods to build on continuing education based in standard e-learning, particularly in resource-limited settings.

While there are limitations in our study because of a small sample size and because not all participants completed the survey, we feel that several valuable lessons from our experience can be used to improve the utility and contribution of MOOCs and other continuing education tools in other rural African settings.

First, we learned that having Internet access is a significant challenge, as highlighted by others (Oyo \& Kalema, 2014; Liyanagunawardena, Williams, \& Adams, 2013). The poor Internet quality minimized the participants' ability to participate in the online forum, and often thwarted attempts at downloading the course materials in a timely manner. The online-to-flash drive provision of this course to the two districts without sufficient Internet access mitigated the accessibility challenge for the participants, though this is 
inefficient and resource-intensive in the long-term, and does not address the exclusion from the online forums. While access to low-definition course videos and one-time bulk downloads would greatly improve accessibility of the course in areas with poor Internet access, the use of online forums is dependent on sufficient Internet in these areas.

Second, attending in-class sessions was linked to successful completion of the course and while participants across the three districts, all of whom were full-time employees, noted the course time commitment as a challenge, class attendance was significant in relation to class completion. The in-class aspect of this course was dedicated to thoroughly understanding the material with the assistance of the course facilitators, and provided an opportunity for class discussions and lectures, and to resolve issues with language barriers.

The close accompaniment provided by the course facilitators likely mitigated the initial start-up challenges for participants, including understanding the online system and how to use online forums, obtaining course lectures, and sufficiently grasping the new presentation of material. During the first inclass session, the facilitators provided a comprehensive review of the online platform, including registration with Coursera and navigating the videos, readings, quizzes and online forum. Each week, the facilitators located all of the readings through HINARI, a World Health Organization program enabling developing countries to access health-related journals. To mitigate challenges with language barriers, the facilitators distributed all of the videos with English subtitles (as provided by the University of Geneva), so that participants could read as well as listen to the content. The impact of dually implementing both the online class and the in-person meetings with close accompaniment suggests a model that can be considered in other settings, including very rural areas.

Third, given the importance of in-class sessions, we recommend that when implementing similar professional development opportunities, employers consider allowing employees to utilize work hours for classes, studying for continuing education activities such as these, or both. The difficulties of dedicating numerous hours a week to this program was noted by the participants in our survey but the participants overwhelmingly believed that this course would help with career advancement and the acquiring of new skills.

\section{Conclusion}

While there were significant barriers to implementation and completion of a MOOC in rural Rwanda, multiple interventions were in place to mitigate challenges and support participants to participate. The PIH flipped classroom experience resulted in a relatively high completion rate, and delivery of the course was refined through experience and challenges met during implementation. Our rural experience yields several lessons (such as facilitating Internet access, in-class guidance and engaging employers) or incorporating MOOCs into capacity-building programs in any setting in order to leverage the potential of online learning to truly shift the educational paradigm in resource-limited areas. 


\section{Competing Interests}

The authors declare no competing interests.

\section{References}

Berrett, D. (2012, February 19). How 'flipping' the classroom can improve the traditional lecture. The Chronicle of Higher Education. Retrieved from https://people.ok.ubc.ca/cstother/How Flipping the Classroom Can Improve the Tradition al Lecture.pdf

Bishop, J., \& Verleger, M. A. (2013, June). The flipped classroom: A survey of the research. Paper presented at 2013 ASEE Annual Conference, Atlanta, GA. Retrieved from https://peer.asee.org/22585

Childs, S., Blenkinsopp, E., Hall, A., \& Walton, G. (2005). Effective e-learning for health professionals and students-barriers and their solutions. A systematic review of the literature-findings from the HeXL project. Health Information and Libraries Journal, 22(Suppl. 2), 20-32. Retrieved from http://www.ncbi.nlm.nih.gov/pubmed/16279973

Christensen, C., Steinmetz, A., Alcorn, B., Bennett, A., Woods, D., \& Emanuel, E. (2013). The MOOC Phenomenon: Who Takes Massive Open Online Courses and Why? Social Science Research Network. Retrieved from http://papers.ssrn.com/sol3/papers.cfm?abstract id=2350964

Cobb, S. C. (2004). Internet continuing education for health care professionals: An integrative review. Journal of Continuing Education in the Health Professions, 24(3),171-80. Retrieved from http://www.ncbi.nlm.nih.gov/pubmed/15490549

Coursera: Meet our partners (2014, August 14). Retrieved from http://www.coursera.org/about/partners

Curran, V. R., \& Fleet, L. (2005). A review of evaluation outcomes of web-based continuing medical education. Medical Education, 39, 561-567.

Friedman, T. L. (2013, January 26). Revolution hits the universities. The New York Times. Retrieved from http://www.nytimes.com/2013/o1/27/opinion/sunday/friedman-revolution-hits-theuniversities.html

Gooding . I, Klaas ,B, Yager.J. D, and Sukon .K (2013). Massive open online courses in public health. Frontiers in Public Health, 1, 59. Retrieved from http://www.ncbi.nlm.nih.gov/pmc/articles/PMC3859968/ 
Liyanagunawardena, T., Adams, A., \& Williams, S. (2013). MOOCs: A systematic study of the published literature 2008-2012. The International Review of Research in Open and Distributed Learning, 14(3), 202-227. Retrieved from http://www.irrodl.org/index.php/irrodl/article/view/1455/2531

Liyanagunawardena, T., Williams, S., \& Adams, A. (2013). The impact and reach of MOOCs: A developing countries' perspective. $e$-Learning Papers (33). Retrieved from http://centaur.reading.ac.uk/32452/

McLaughlin, J., Roth, M., Glatt, D., Gharkholonarehe, N., Davidson, C., Griffin, L. M., Esserman, D. A., Mumper, R. J. (2014). The flipped classroom: A course redesign to foster learning and engagement in a health professions school. Academic Medicine, 89(2), 236-43. Retrieved from http://www.ncbi.nlm.nih.gov/pubmed/24270916

Oyo, B., \& Kalema, B. (2014). Massive open online courses for Africa by Africa. The International Review of Research in Open and Distributed Learning, 15(6). Retrieved from http://www.irrodl.org/index.php/irrodl/article/view/1889

Pappano, L. (2012, November 2). The Year of the MOOC. The New York Times. Retrieved from http://www.irrodl.org/index.php/irrodl/article/view/1889

\section{Athabasca \\ University}

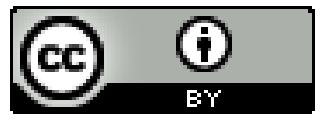

